\title{
Numerical and experimental investigation of the flow separation over NREL's S822 aerofoil and its control by suction and blowing
}

\author{
Nazar Aldabash ${ }^{1,2, *}$, Andrew Wandel ${ }^{1}$, Abdul Salam Darwish ${ }^{3}$, and Jayantha Epaarachchi ${ }^{4}$ \\ ${ }^{1}$ School of Mechanical and Electrical Engineering USQ, Toowoomba Campus, 4350 Australia \\ ${ }^{2}$ University of Diyala College of Engineering, Iraq \\ ${ }^{3}$ University of Bolton, Deane Rd, Bolton BL3 5AB, England \\ ${ }^{4}$ Centre for Future Materials USQ, Toowoomba Campus, 4350 Australia
}

Received: 1 November 2020 / Received in final form: 21 November 2020 / Accepted: 22 November 2020

\begin{abstract}
In this study, a numerical and experimental investigation for the flow separation over $170 \mathrm{~mm}$ chord, the NREL S822 aerofoil low Reynolds number wind turbine blade aerofoil section has been investigated at $15.8 \mathrm{~m} / \mathrm{s}$ wind speed using suction and blowing techniques for the locations between 0.15 and 0.41 of the chord to improve aerodynamic characteristics of a wind turbine rotor blade. In a numerical study, twodimensional aerofoil (i.e. NREL S822), using Shear Stress Transport (SST $\left(\gamma-R e_{\theta}\right)$ ) turbulence model, is presented. Careful selection for the number of mesh was considered through an iterative process to achieve the optimum mesh number resulted in optimum values for the ratio of lift to drag coefficients $\left(C_{L} / C_{D}\right)$. Values of the lift coefficient, drag coefficient, and separation location were investigated at an angle of attack $18^{\circ}$. Flow separation is monitored and predicted within the numerical results at the tested angles, which has been compared with the experimental results and should a fair agreement. The results revealed that the aerodynamic characteristics of NERL S822 aerofoil would be improved using the suction technique more than the suction and blowing techniques and there is a delay of flow separation with the increase of blowing or suction volumetric flow rate. Using these two techniques and careful selection of the mesh numbers with the right angle of attack can improve the aerofoil characteristics and therefore lead to improve the turbine performance characteristics.
\end{abstract}

\section{Introduction}

The significant increase in the development of wind turbines in the last few decades has made it challenging to control wind turbines in the same way as before. Current turbines depend on a modern control system that guarantees secure and optimal operation. It is believed that the wind has the potential to provide $20 \%$ of global electricity production in 2030, creating 2.4 million new jobs and reducing $\mathrm{CO} 2$ emissions by more than 3.3 billion tonnes per year. Worldwide wind capacity reached $645 \mathrm{GW}$ in 2019 [1].

Researchers studied numerically and experimentally the separation control on the aerofoil model NACA 2412 using the jet blowing at different angles of attack $\left(0^{\circ}-30^{\circ}\right)$ up and beyond the stall angle and at Reynolds numbers greater than 340 000. The results show that the jet blowing is active for flow separation control [2]. Jawad et al. [3] get

\footnotetext{
* e-mail: nmald3@gmail.com
}

the same technique and get similar results but with NACA 4415 aerofoil at angles of attack $\left(5^{\circ}, 10^{\circ}\right.$, and $\left.15^{\circ}\right)$. However, for large separation regions, the jet blowing is not sufficient to remove flow separation. It has been found that Computational Fluid Dynamics (CFD) simulation is an efficient and accurate way to predict control flow separation via jet blowing technology. The results reveal that by using the mentioned technique, there is a high increase in lift, even with a zero Angle of Attack (AoA). Also, with large separation, it is not easy to control flow separation completely.

Genç et al. [4] investigated the performance of transition and turbulence flow at low Reynolds number. In this study, suction and blowing techniques to mitigate a laminar separation bubble have been evaluated. Besides, numerical simulation using the K-KL-w model has been conducted. The results showed that LSB is not completely removed through a single blowing or suction technique. Nevertheless, it is either delayed towards the trailing edge or reduced. The researchers also found that a large amount of suction and a small amount of blowing is better for 
NREL's S822 Airfoil (s822-nr) http://airfoiltools.com/airfoil/details?airfoil=s822-nr
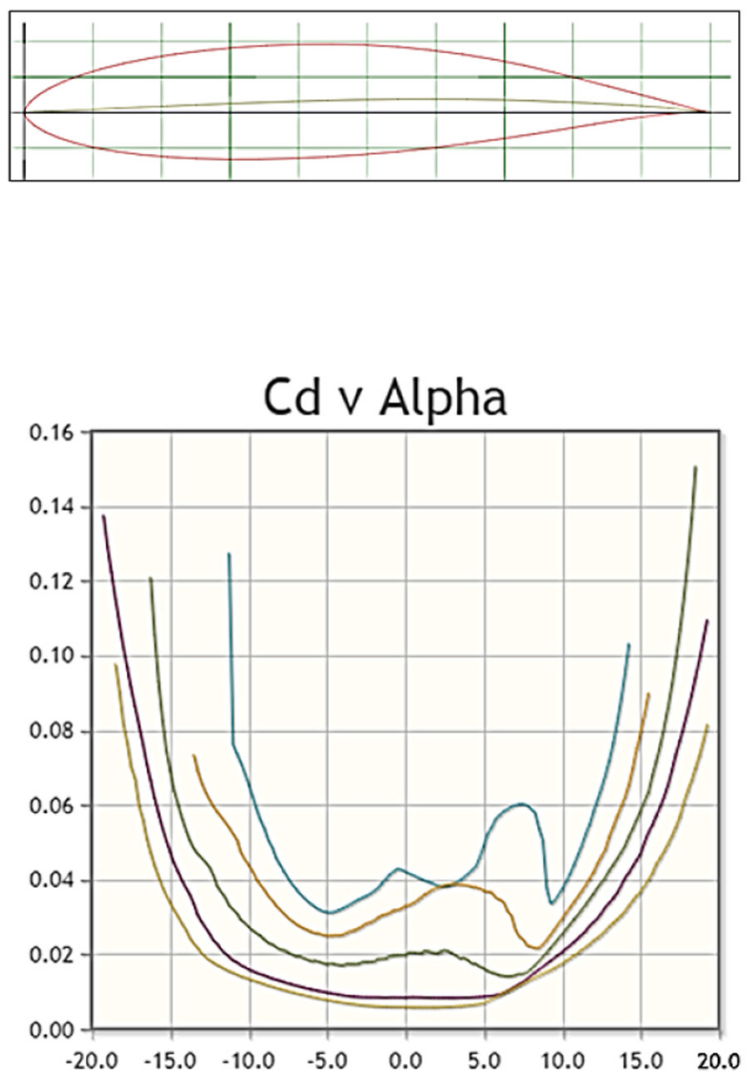

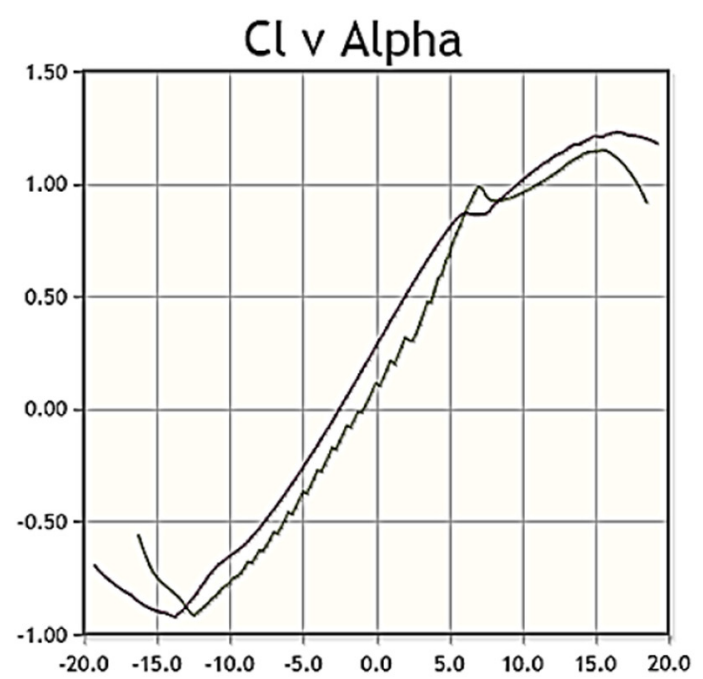

Cl/Cd v Alpha

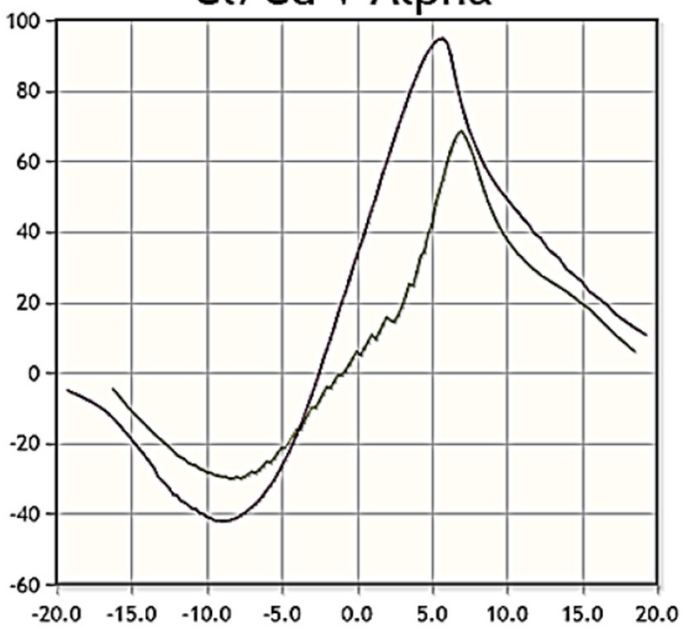

Fig. 1. Aerodynamic characteristics of NREL's S822 Aerofoil.

eliminating the laminar separation bubble depending on the location of active flow control. Hence, the aerodynamic characteristics of aerofoil were improved.

Chawla et al. [5] investigated a constant suction technique for controlling boundary layer separation over NACA0012 and S814 aerofoils at low Reynolds numbers, ranging from (10 000-100 000) for small HAWT. The air was drawn from the upper surface through multiple locations, depending on an increase in the lift coefficient. It was found that the efficiency of the aerofoil increased and there was an increase in lift and a decrease in drag. The research that has been reviewed reveals that the separation flow could be mitigated or suppressed, or the stall angle could be delayed by using active flow control actuators resulting in an increase in lift curve and a decrease in drag curve and this would lead to an improvement in the efficiency of the aerofoil.

Gross and Fasel [6], studied boundary layer separation over the NREL S822 at Reynolds number of 100000 using flip-flop jets, pulsed vortex generator jets, and plasma techniques. It has been found that using active flow control leads to mitigating the unsteady loads and hence improving the turbine lift.

In this paper, a numerical and experimental study has been investigated to mitigate the effect of adverse pressure gradient and delay the flow separation by using a suction/ blowing techniques as active flow control. This may lead to improved wind turbine performance.

The researches that have been reviewed reveal that the separation flow could be mitigated or suppressed, and the stall angle could be delayed by using active flow control actuators resulting in an increase in lift curve and a decrease in drag curve, and this would lead to an improvement in the efficiency of the aerofoil and hence, improve the annual energy production.

Although these improvements may have worth, none of them has been investigated to the state of being tried in a full-scale wind turbine aerofoil. As a result, this requires a more advanced Aerofoil.

Figure 1 depicts the profile of the NRELS822 aerofoil and its aerodynamic characteristics (lift/drag coefficients). 
Table 1. Classification chart for AFC techniques [7].

\begin{tabular}{|c|c|c|c|c|c|}
\hline & Devices & $\begin{array}{l}\text { Geometric }(\mathrm{G}) / \\
\text { Fluidic }(\mathrm{F}) / \\
\text { Plasma }(\mathrm{P})\end{array}$ & $\begin{array}{l}\text { Leading } \\
\text { Edge (LE)/ } \\
\text { Trailing } \\
\text { Edge (TE)/ } \\
\text { Mid-Chord (MC) }\end{array}$ & $\begin{array}{l}\text { Inc. Lift (I)/ } \\
\text { Dec. Lift (D)/ } \\
\text { Delay Stall } \\
\text { (DS) }\end{array}$ & $\begin{array}{l}\text { Steady (S), } \\
\text { Unsteady } \\
\text { (U) }\end{array}$ \\
\hline 1 & Traditional trailing-edge flaps & $\mathrm{G}$ & $\mathrm{TE}$ & $\mathrm{I} / \mathrm{D}$ & $\mathrm{S} / \mathrm{U}$ \\
\hline 2 & Nontraditional trailing-edge flaps & $\mathrm{G}$ & $\mathrm{TE}$ & $\mathrm{I} / \mathrm{D}$ & $\mathrm{S} / \mathrm{U}$ \\
\hline 3 & Microtabs & $\mathrm{G}$ & $\mathrm{TE}$ & $\mathrm{I} / \mathrm{D}$ & $\mathrm{S} / \mathrm{U}$ \\
\hline 4 & Miniature trailing-edge effectors & $\mathrm{G}$ & $\mathrm{TE}$ & $\mathrm{I} / \mathrm{D}$ & $\mathrm{S} / \mathrm{U}$ \\
\hline 5 & Microflaps & G & $\mathrm{TE}$ & $\mathrm{I} / \mathrm{D}$ & $\mathrm{S} / \mathrm{U}$ \\
\hline 6 & Active stall strips & $\mathrm{G}$ & LE & $\mathrm{D}$ & S \\
\hline 7 & Vortex generators & $\mathrm{G}$ & LE & DS & $\mathrm{S}$ \\
\hline 8 & Blowing and suction & $\mathrm{F}$ & $\mathrm{LE} / \mathrm{TE}$ & DS & $\mathrm{S} / \mathrm{U}$ \\
\hline 9 & Circulation control & $\mathrm{F}$ & $\mathrm{TE}$ & $\mathrm{I} / \mathrm{D}$ & $\mathrm{S}$ \\
\hline 10 & Plasma actuators & $\mathrm{P}$ & LE & DS & $\mathrm{S}$ \\
\hline 11 & Vortex generator jets & $\mathrm{F}$ & LE & DS & $\mathrm{S} / \mathrm{U}$ \\
\hline 12 & $\begin{array}{l}\text { High-frequency micro } \\
\text { vortex generators }\end{array}$ & $\mathrm{G}$ & LE & DS & $\mathrm{U}$ \\
\hline 13 & Synthetic jets & $\mathrm{G} / \mathrm{F}$ & $\mathrm{LE}$ & DS & $\mathrm{U}$ \\
\hline 14 & Active flexible wall & $\mathrm{G}$ & LE & DS & $\mathrm{U}$ \\
\hline 15 & Shape change airfoil & $\mathrm{G}$ & $\mathrm{MC}$ & I & $\mathrm{S} / \mathrm{U}$ \\
\hline
\end{tabular}

\subsection{Active flow control techniques (AFC)}

Active flow control methods that include continuous blowing or suction processes have evolved to enhance the aerodynamic characteristic of the aerofoil profile. The main role of active flow control is controlling blade loads and aero-elastic reaction. Active flow control techniques (AFC) can be categorised into four layers. The first layer is defined as a geometric or fluidic technique. The place of the AFC system (near the trailing edge, near the leading edge and the mid-chord) is indicated in the second layer Table 1. The third category is related to improving the aerodynamic characteristics like (for instance increasing the lift, decreasing the drag and delaying of flow separation), and the last layer describes the flow behaviour around blade aerofoil.

\subsection{Flow separation}

When the airflow passes through the blade's aerofoil section, the flow will remain attached to the suction side of the aerofoil unless it exceeds the stall angle. However, if a stall happens, the flow will be detached, and this situation is called "separation" (Fig. 2), leading to the flow reverse and the lift curve will be dropped [8].

\section{Wind turbine aerofoil families}

At Delft University, the National Renewable Energy Laboratory (NREL) and Riso National Laboratory, aerofoils have been designed with a significantly large

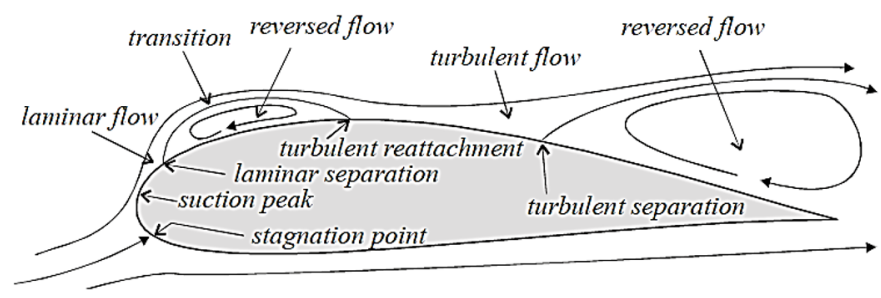

Fig. 2. Flow regimes within separation above aerofoil [8].

number of low Reynolds numbers [3,5]. These aerofoils have been invented for the wind turbine blade to eliminate the laminar separation bubbles that may occur when using wing aerofoils such as the NACA or NASA LS families [9]. The NREL's S-Series aerofoils can be classified into "thin" (11-15\%) and "thick" (16-21\%) aerofoils [10]. This study will focus on the thin aerofoil family that is accommodated for fixed pitch and variable rotational speeds of wind turbines. It will determine a specific aerofoil for each root, mid, and tip of the blade, depending on the proposed specification of the diameter of the wind turbine rotor. The blade in the root area requires the greatest thickness ratio (maximum thickness to chord ratio) for better structural performances. The thinner aerofoil is needed for the blade tip to mitigate drag and blade losses [11] and increased power output of horizontal axis wind turbines [12].

\section{Methodology}

The methodology consists of numerical analysis (CFD) supported by experiments done to verify the numerical approach. 


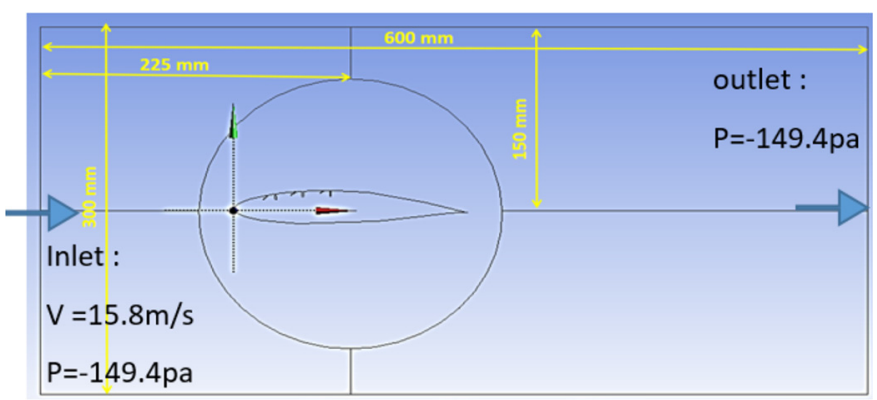

Fig. 3. The computational domain of the NRELS822 aerofoil.

Table 2. Optimum computational conditions for aerofoil simulations.

\begin{tabular}{ll}
\hline Aerofoils & NRELS822 and \\
& NRELS823 aerofoils \\
\hline Simulation type & Unsteady Simulation \\
Fluid material & Air \\
Temperature & $288 \mathrm{~K}$ \\
Kinematic viscosity & $1.4607 \times 10^{-5} \mathrm{~m}^{2} / \mathrm{s}$ \\
Reynolds number & 179489 \\
Density & $1.225 \mathrm{~kg} / \mathrm{m}^{3}$ \\
Wind speed at test section & $15.8 \mathrm{~m} / \mathrm{s}$ \\
Turbulent model & $\mathrm{SST}\left(\gamma-\operatorname{Re}_{\theta}\right)(4 \mathrm{eqn})$ \\
Inlet and outlet static pressure & $-149.4 \mathrm{~Pa}$ \\
Inlet intermittency gamma $(\gamma)$ & 1 \\
Inlet turbulent intensity & $5 \%$ \\
The angle of attack $($ AoA $)$ & $18^{\circ}$ \\
\hline
\end{tabular}

\subsection{The computational fluid dynamics CFD analysis}

In this section, a computational fluid dynamics CFD for two-dimensional (2D) aerofoil (i.e. NREL-S822 aerofoil), using Transition ( $\operatorname{SST}\left(\gamma-R e_{\theta}\right)$ ) turbulence model, has been investigated. The blade created by "ANSYS FLUENT 2020 R1 ACADEMIC" and, with the assistance of the aerofoil tools website, http://aerofoiltools.com/plotter/ index The pre-process of ANSYS-Fluent is the Workbench with which the models are designed. Computational domain of the NREL S822 aerofoil is shown in Figure 3. The optimal boundary conditions for the simulation process can be illustrated in Table 2 .

The optimum number of CFD mesh was found to be (95) by an iterative process when the predicted values for CL and CD were the same as the mesh number increased, as shown in Table 3.

\section{Experimental approach}

Two techniques were experimentally investigated to control the flow's separation, namely the suction technique
Table 3. Iterative process for the optimum number of mesh.

\begin{tabular}{llll}
\hline & No. of cells & CL & CD \\
\hline Case 1 & 22491 & 0.64495 & 0.183889 \\
Case 2 & 33116 & 0.72 & 0.140261 \\
Case 3 & 57141 & 0.75 & 0.13 \\
Case 4 & 94269 & 0.803 & 0.112929 \\
Case 5 & 144027 & 0.804 & 0.114152 \\
\hline
\end{tabular}

and the blowing technique. A prototype manufactured for the blade's aerofoil section is the NREL S822 aerofoil. The prototype model was designed by Creo software and manufactured using a 3D printing machine. Pressure tapping and slots at three locations for blowing technique and three other locations for the suction technique were formed as seen in Figure 4, where B symbol denoted for blowing and the S Symbol denoted for suction. Some techniques are used for either blowing or suction, and others are used for both together, which indicates that they are used for blowing and suction in the same process.

\subsection{The suction and blowing configurations setup}

Nine tests using blowing and suction techniques were conducted for the S822 aerofoil section, Table 4. The suction and blowing velocities per slot were $10 \mathrm{~m} / \mathrm{s}$ for blowing and $-5 \mathrm{~m} / \mathrm{s}$ for suction.

\section{Results and discussion}

The results revealed that the experimental and numerical simulation tests have a good agreement. Pressure distribution for the baseline case (no AFC) was presented for CFD and empirical tests, as shown in Figure 5. Flow visualisation for the flow pattern and behaviour with an inlet velocity of $15.8 \mathrm{~m} / \mathrm{s}$ and AoA of $18^{\circ}$ has been obtained for CFD and the experimental tests (Fig. 6). Flow separation point and trailing edge separation were investigated. Velocity profiles reveal the effect of the adverse pressure gradient. However, when an active flow control technique was applied, the flow separation was mitigated, and the flow separation point was moved towards the trailing edge (Fig. 7).

The results of lift-to-drag ratios with their percentages of improvement/unimprovement cases for all tested cases were presented in Figure 8, for high/low angles of attack. In this respect, $9^{\circ}$, was selected as the low AoA and $18^{\circ}$ was selected as the high AoA. The red dash line represented the baseline case. S1B3 setup showed the highest percentage of improvement of lift-to-drag ratio for high AoA $\left(18^{\circ}\right)$, while for the low AoA $\left(9^{\circ}\right)$, the best technique setup was found to be S3. However, S1 has shown an improvement of $71 \%$ at high AoA and $14 \%$ at low AoA. Consequently, this setup showed the best for both (high and low AoA). 


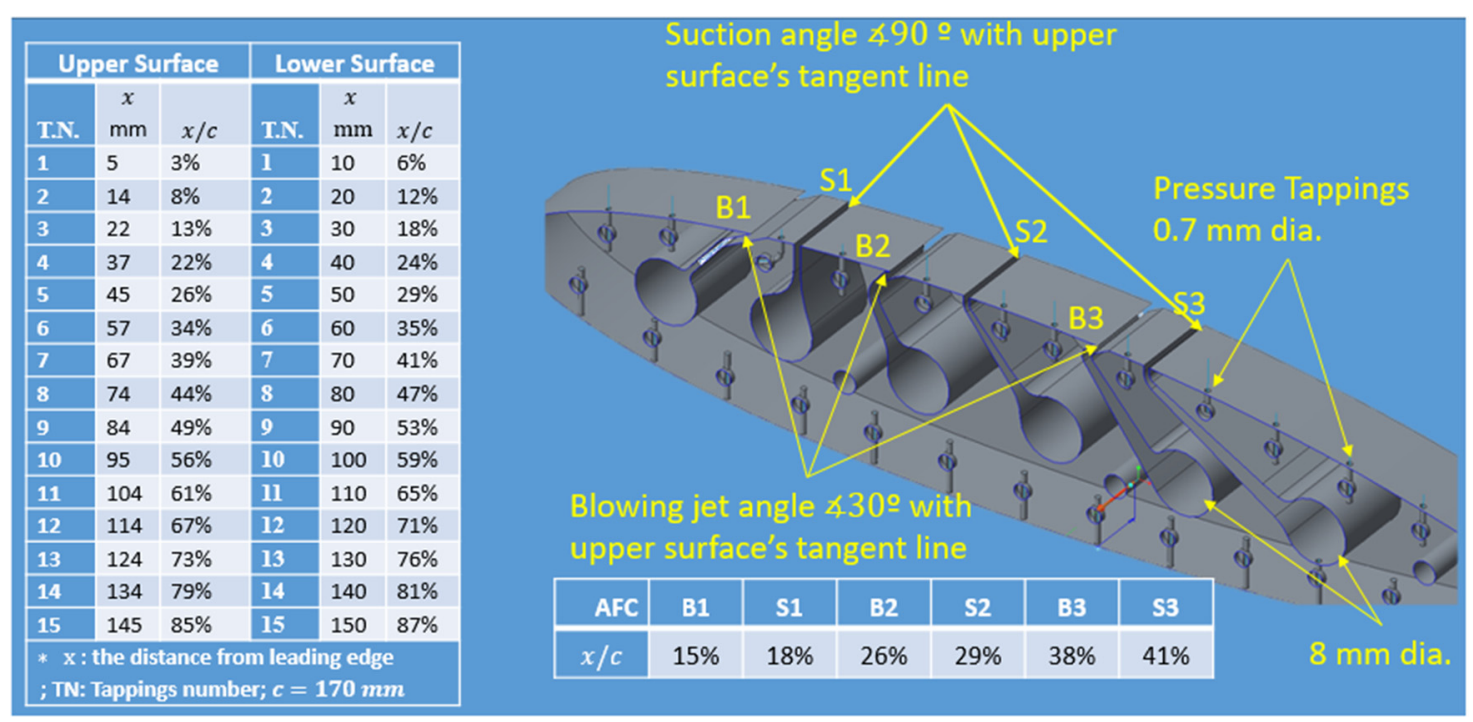

Fig. 4. The NREL's S822 Aerofoil prototype model: blowing (B) and suction (S) slots locations along the aerofoil profile chord and the pressure tapping distributed around the section.

Table 4. Blowing and suction configurations setup.

\begin{tabular}{lll}
\hline AFC methods & & Velocity/slot \\
\hline Blowing cases only & B1, B2, and B3 & \\
Suction cases only & S1, S2, and S3 & $10 \mathrm{~m} / \mathrm{s}$ for blowing and $-5 \mathrm{~m} / \mathrm{s}$ for suction \\
Suction and blowing & S1B3, S2B3, and S3B3 & \\
\hline
\end{tabular}

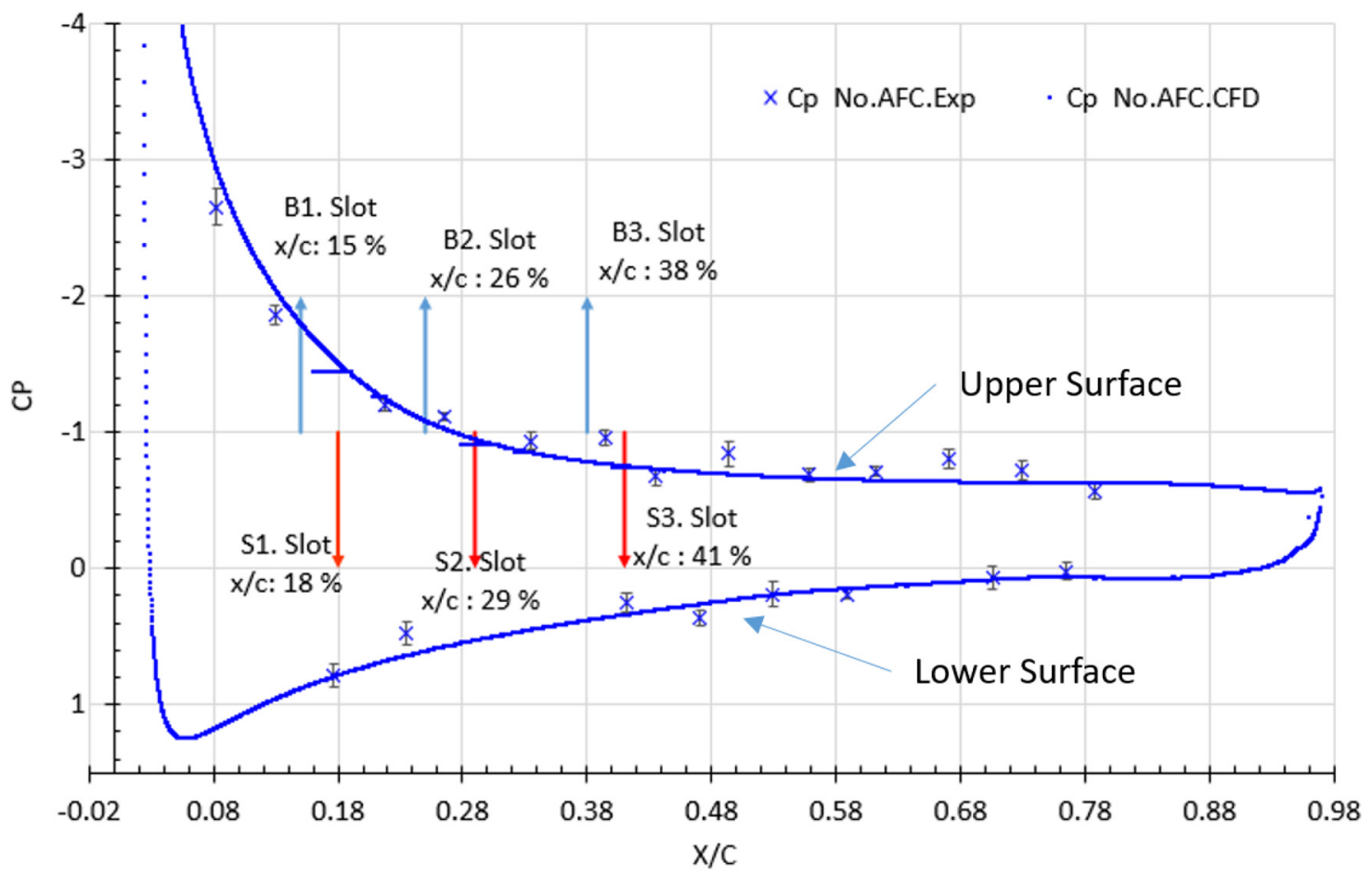

Fig. 5. Pressure coefficients around the aerofoil profile of the baseline case (without AFC). 


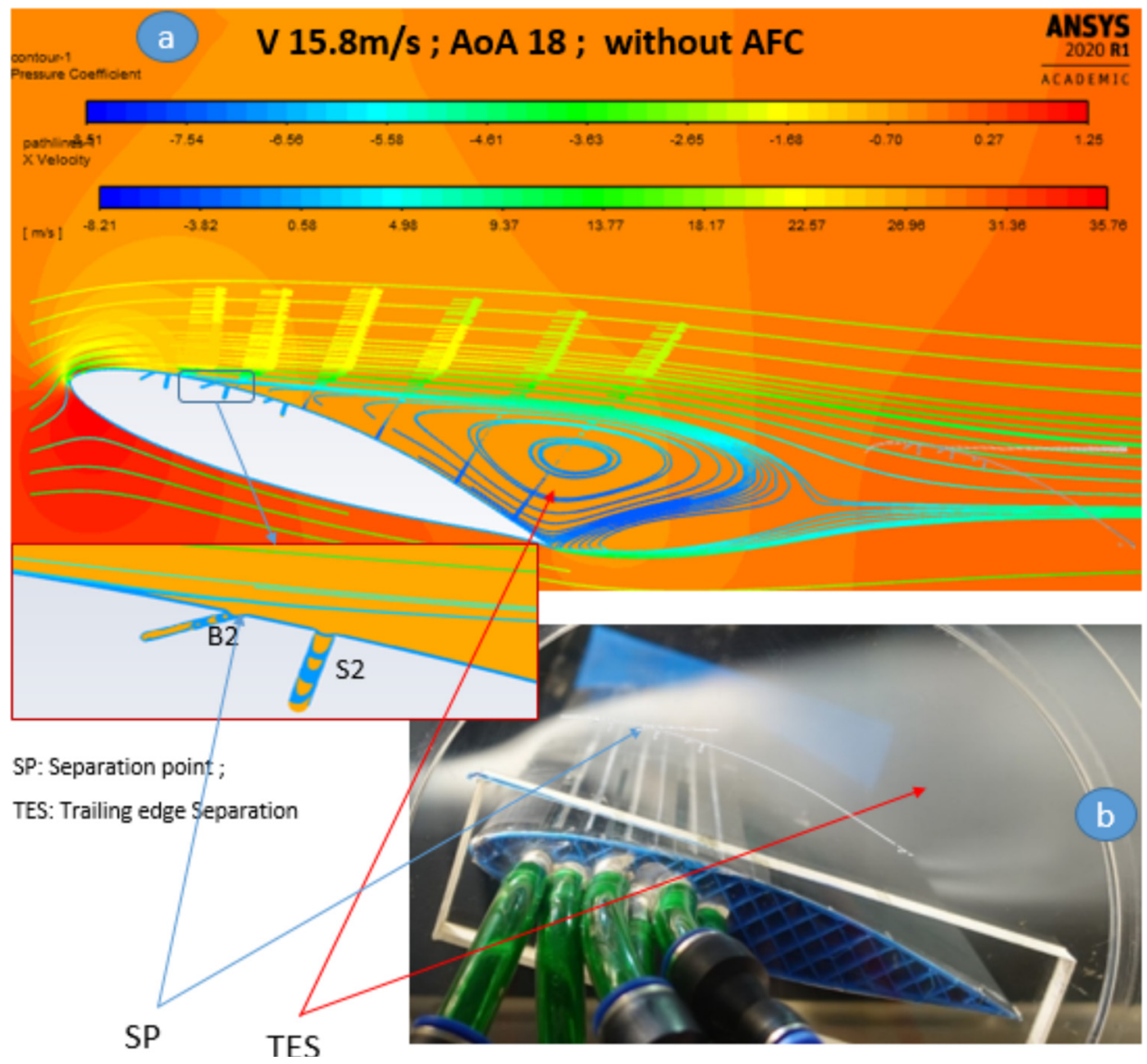

Fig. 6. Results of Flow visualisation around the aerofoil for the baseline case (no AFC).

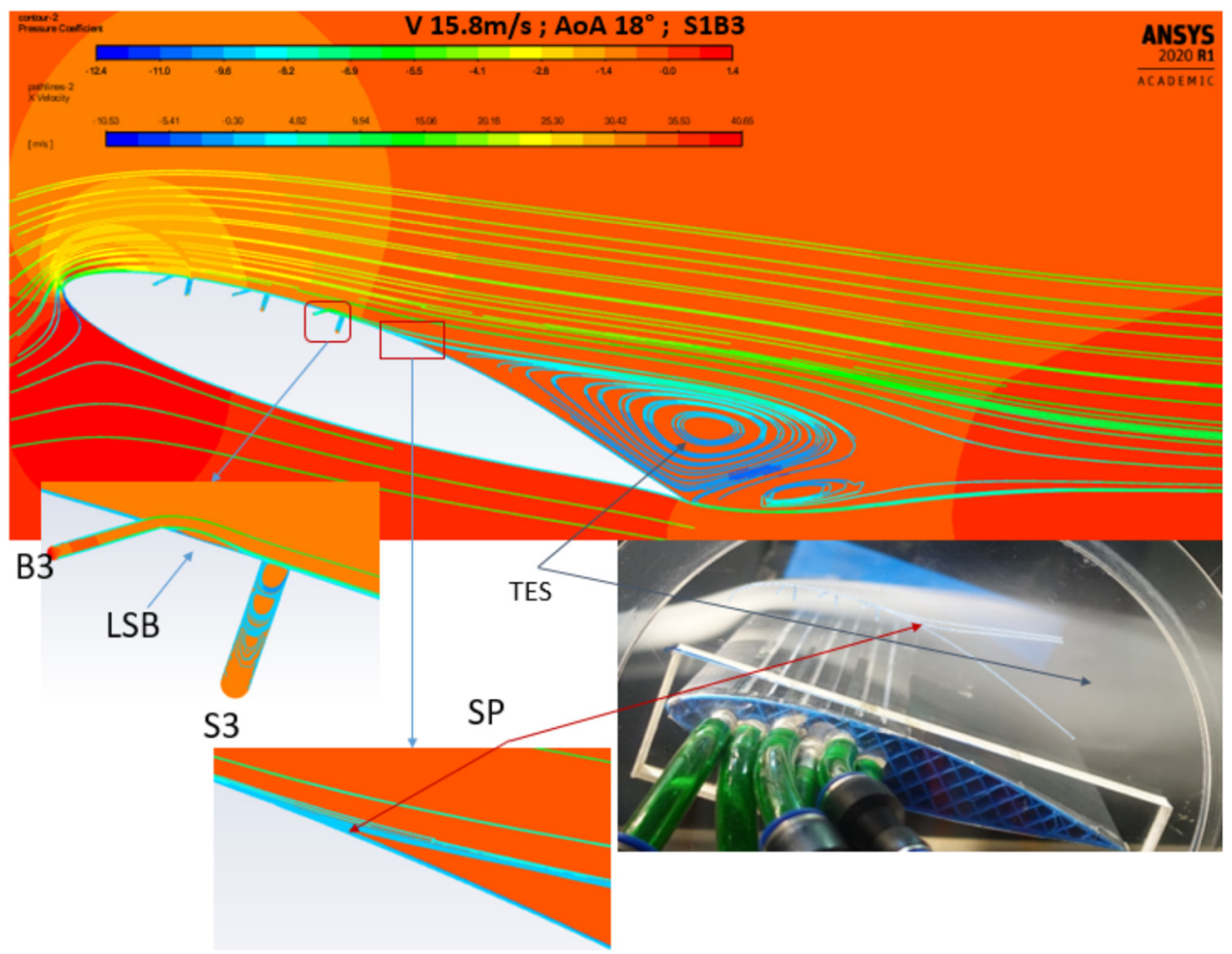

Fig. 7. Results of Flow visualisation around the aerofoil for the S1B3 case. 
(a)

The percentages of lift to drag ratio for $\mathrm{S} 822, \mathrm{AoA} 18^{\circ}$ and inlet Vel. $15 \mathrm{~m} / \mathrm{s}$

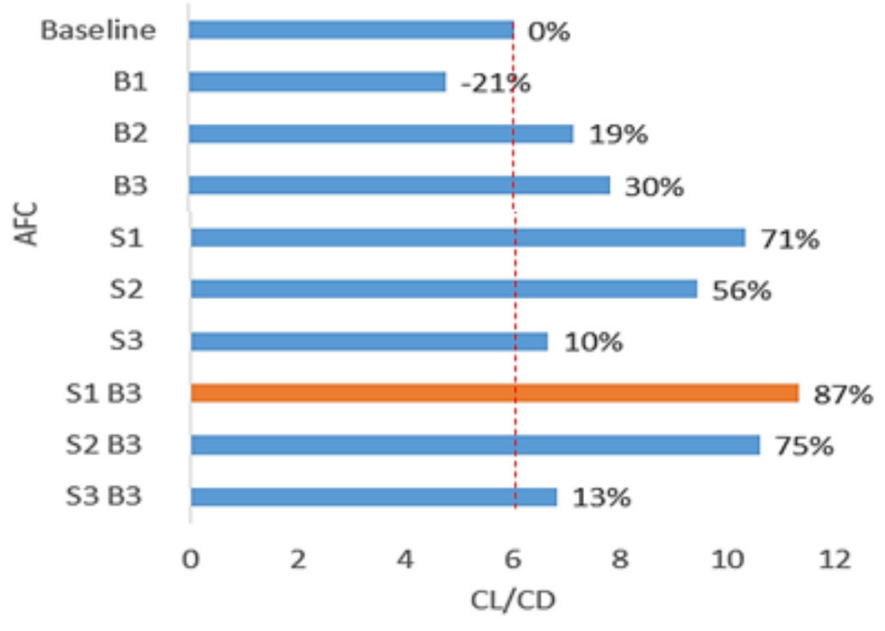

(B) The percentages of lift to drag ratio for $\mathrm{S} 822, \mathrm{AoA}^{\circ}$ and inlet Vel. $15.8 \mathrm{~m} / \mathrm{s}$

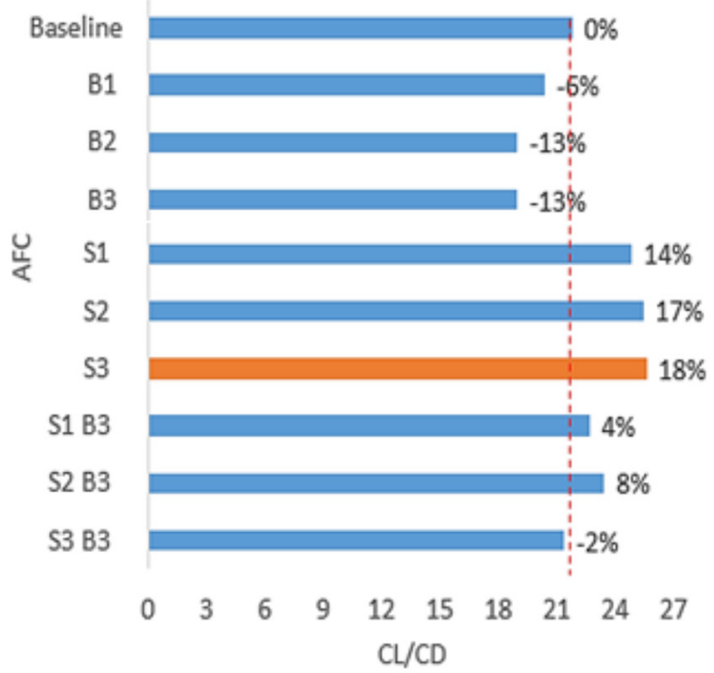

Fig. 8. The percentages of lift-to-drag ratios CL/CD [dimensionless] for S822 with AFC methods: (a) for AoA of $18^{\circ}$; (b) for AoA of $9^{\circ}$.

\section{Conclusions}

From the numerical analysis, it can be seen that there is a change in the lift-to-drag ratio due to the suction and blowing techniques. So, from the blowing side, the B3 slots, which is placed at $38 \%$ of chord, have resulted in $30 \%$ improvement in the aerofoil characteristics for high angle of attack $\left(18^{\circ}\right)$ based on the baseline case.
However, with a low angle of attack $\left(9^{\circ}\right)$, there is no improvement noticed when the blowing technique had been considered.

In the case of only suction techniques, when S1 slots considered at position close or $18 \%$ of the chord length, the best possibility of results was noticed. In this respect, the aerofoil performance has experienced $71 \%$ of improvements at a high angle of attack $\left(18^{\circ}\right)$ and $14 \%$ at a low angle of attack $\left(9^{\circ}\right)$. The technique of S3 with low AoA, give the best lift to drag (18\%) while S1B3 in high AoA, give 87\% but here, two slots will be used.

For a good design, it is necessary to use a single slot for all angles of attack $\left(0-21^{\circ}\right)$. The researchers showed that the S1 would be suitable for all angles of attack and is considered the best engineering method when designing these technologies as creating one slot is better than two. The fact that the two will require a significant amount of energy consumption necessary to provide for the technology to work.

\section{Future research}

Three-dimensional rotor simulation can support the numerical predictions and experimental findings. A study to optimise the size of the blowing and suction holes could lead to optimum aerodynamic characteristics and maximise the rotor performance.

\section{References}

1. A.S. Darwish, R. Al-Dabbagh, Wind energy state of the art: present and future technology advancements, Renew. Energy Environ. Sustain. 5, 7 (2020).

2. M.J. Jalal, H.Y. Assim, M. Yasser Ahmed, Control of separation for NACA 2412 aerofoil at different angles of attack using air blowing, Eng. Technol. J. 28, 5138-5150 (2010).

3. A.M. Jawad, M.Z. Khelifa, M.S. Abdullateef, Y.A. Mahmood, Enhancement of wind turbine performance using air- blowing technique by Modified Strong Implicit Procedure (MSIP) optimization solver method, Eng. Technol. J. 32, 1580-1601 (2014)

4. M.S. Genç, Ü. Kaynak, H. Yapici, Performance of transition model for predicting low Re aerofoil flows without/with single and simultaneous blowing and suction, Eur. J. Mech. B Fluids 30, 218-235.

5. J.S. Chawla, S. Suryanarayanan, B. Puranik, J. Sheridan, B. G. Falzon, Efficiency improvement study for small wind turbines through flow control, Sustain. Energy Technol. Assess. 7, 195-208 (2014)

6. A. Gross, H. Fasel, Flow control for NREL S822 wind turbine aerofoil, Aerosp. Mech. Eng. (2017)

7. S.J. Johnson, C.P.C.v. Dam, Active load control techniques for wind turbines, University of California, 2008 
8. G.P. Corten, Flow separation on wind turbine blades, PhD thesis dissertation, Utrecht University The Netherlands, 2001.

9. Y.M. Shkara, Aerodynamic analysis and optimum blade design of HAWT rotor with winglet the Degree of Master, University of Technology, Baghdad, 2014

10. J.L. Tangier, D.M. Somers, NREL Aerofoil families for HAWTs, A National Laboratory of the U.S. Department of Energy, 1995.
11. M. Buhl, Wind turbine aerofoil families, National Renewable Energy Laboratory, 2012.

12. H. Cao, Aerodynamics analysis of small horizontal axis wind turbine blades by using 2D and 3D CFD modelling, MSc (by research), University of the Central Lancashire Preston, England, 2011.

Cite this article as: Nazar Aldabash, Andrew Wandel, Abdul Salam Darwish, Jayantha Epaarachchi, Numerical and experimental investigation of the flow separation over NREL's S822 aerofoil and its control by suction and blowing, Renew. Energy Environ. Sustain. 6, 5 (2021) 